\title{
Questionário Virtual Para o Ensino de Probabilidade
}

\author{
Virtual Quiz to Teach Probability
}
Cristiana Andrade Poffal ${ }^{1}$, Maurício Osmall Jung ${ }^{2}$, André Meneghetti ${ }^{3}$ e Cinthya Schneider Meneghetti ${ }^{4}$

1,2,3,4 Universidade Federal do Rio Grande, Brasil

\begin{abstract}
Resumo
Considerando que o conceito de probabilidade é fundamental para a formação do indivíduo devido à forma de raciocínio, à aplicabilidade e também ao campo profissional promissor, apresentamos uma proposta que sugere, num primeiro momento, uma problematização para, depois, conceituar e definir os termos que envolvem a Probabilidade. Segue-se essa metodologia, uma vez que a história da probabilidade acontece nessa ordem: primeiro surgem os problemas, depois, os conceitos e as definições. Para isso, utiliza-se a tecnologia através de dois questionários virtuais e interativos a serem resolvidos pelos discentes. Assim, aproxima-se o educando do assunto, já que este participa da construção dos conceitos e definições.
\end{abstract}

Palavras-chave: Jogos. Probabilidade. Tecnologia.

\begin{abstract}
As the concept of probability is fundamental to the individual formation due to its form of reasoning,to its applicability and to the professional field, we present a proposal that suggests, first, a problematization then the definition of the probability jargon. It follows that methodology, since the history occurs in this order: first the problems arise, then the concepts and definitions. So, we use the technology in two virtual and interactive quizzes to be solved by students, since playing has an important role during the constrution of the concepts and definitions, the student becomes easily closer to the whole subject.
\end{abstract}

Keywords: Games. Probability. Technology. 


\section{Introdução}

A probabilidade teve origem por volta do século XVII com Pascal e Fermat que resolveram questões relacionadas a jogos de azar e "em sua histórica correspondência de 1654, refletiram sobre outros problemas relacionados com o problema dos pontos [...]. Foi esse trabalho de Pascal e Fermat que lançou as bases da teoria matemática da probabilidade"(Eves (2002)). A partir disso, segundo Boyer (1974), “Huygens em 1657 publicou um pequeno folheto, De ratiociniis in ludo aleae (Sobre o raciocínio em jogos de dados)". Nos dois séculos seguintes, estudiosos como Bernoulli, Moivre, Euler, Lagrange, Laplace, entre outros, formalizaram os conceitos.

A ideia de nossa proposta é a mesma no que se refere a construção do conhecimento. Incentivar o aluno a entender a probabilidade informalmente com atividades não tradicionais e, logo após, inserir os conceitos tradicionais formais. Tivemos como inspiração os trabalhos: Uma proposta para o estudo de probabilidade no ensino médio (Lopes et al. (2011)), Uma Proposta Didático-Pedagógica para o estudo da Concepção Clássica de Probabilidade (Lopes (2011)) e Jogo dos Discos (Caetano e Paterlini (2010)).

Estamos vivendo um momento de ascensão tecnológica em especial no mundo da informática. Atualmente é raro um jovem não dispor de um aparelho de celular, computador, tablet, entre outros. Mesmo aqueles que possuem baixa renda, que não possuem aparelhos eletrônicos como esses, têm oportunidade de utilizá-los, seja na sua escola, seja em uma lan house, na casa de um amigo, entre outras possibilidades. No mercado de trabalho vemos cada vez mais a exigência de conhecimentos básicos na área. A inserção da tecnologia nos dias atuais vai muito além de um simples lazer, já é, sem dúvida, uma necessidade.

A escola deve participar desse aprendizado. As noções básicas de informática podem ser aplicadas para o aprendizado dos conteúdos da ementa escolar. Algumas práticas já são usadas e, a cada dia, aperfeiçoadas. Podemos citar como exemplo o uso de editores de textos, uso de softwares como Cabri e Geogebra (no estudo de geometria), uso de ferramentas html, entre outros.

Uma das formas de diversão dos jovens são os jogos on-line. Tais jogos costumam ser feitos no formato swf (shock wave flash) e possuem uma interface amigável que prende a atenção dos usuários. Com conhecimento básico em programação e criatividade é possível desenvolver um jogo nesse formato. A quantidade de memória requerida para funcionamento e execução desses jogos é pequena, na ordem de $1 \mathrm{Mb}$, o que o torna executável na maioria dos aparelhos eletrônicos com capacidade computacional.

Nossa proposta visa usar esse formato para desenvol- ver dois questionários que ao mesmo tempo prendam a atenção do estudante e estimulem a construção do conhecimento em probabilidade, pois segundo Corbalán (2002) esses conteúdos são de grande dificuldade para os estudantes do Ensino Médio, por motivos intrínsecos e pela falta de contato anterior com os conceitos, por isso o autor considera que deveria ser feito um grande esforço para apresentar esses assuntos de forma lúdica.

Assim, uma vez que se entenda a probabilidade de maneira informal, será natural a formalização dos conceitos.

Além disso, com a Proposta Pedagógica para o Ensino Médio Politécnico e Educação Profissional Integrada ao Ensino Médio - 2011-2014 do governo do estado do Rio Grande do Sul, a Organização Curricular do Ensino Médio sofreu mudanças. Assim, os três anos do Ensino Médio ficaram divididos em Formação Normal e Parte Diversificada. Conforme essa proposta

\begin{abstract}
entende-se por formação geral (núcleo comum), um trabalho interdisciplinar com as áreas de conhecimento com o objetivo de articular o conhecimento universal sistematizado e contextualizado com as novas tecnologias, com vistas à apropriação e integração com o mundo do trabalho [...] entende-se por parte diversificada (humana - tecnológica - politécnica), a articulação das áreas do conhecimento, a partir de experiências e vivências, com o mundo do trabalho, a qual apresente opções e possibilidades para posterior formação profissional nos diversos setores da economia e do mundo do trabalho.(SEDUC/RS (2011-2014))
\end{abstract}

Na prática, significa que no primeiro ano do Ensino Médio acrescentam-se dois períodos semanais de Seminário Integrado, no turno normal, referentes à Parte Diversificada. No segundo ano são acrescidos três períodos de Seminário Integrado e, no terceiro, quatro períodos. Devido a esses acréscimos, a carga horária semanal de algumas disciplinas tem sido reduzida. É o que acontece com as disciplinas de Matemática e de Língua Portuguesa, pois possuem um número maior de períodos semanais. Por exemplo, se o primeiro ano possuía quatro períodos de Matemática semanalmente, passará a ter somente três.

Nesse contexto, o presente trabalho mostra-se de grande interesse, pois, geralmente, o professor leva cerca de 12 aulas para ensinar Probabilidade e com a nova Proposta Pedagógica para o Ensino Médio, o professor terá menos tempo em sala de aula e atividades extra classe serão, mais do que nunca, essenciais. A proposta de nossa atividade pode ser realizada integral ou parcialmente na escola, sendo assim, o professor compensa a redução da carga horária semanal, uma vez que a atividade proporcionará a construção prévia dos conhecimentos 
pelos alunos. Portanto, se essa proposta for aplicada parcialmente na escola, serão necessárias menos do que 12 aulas para o ensino de Probabilidade.

Apresentaremos na seção 2, uma caracterização da nossa proposta e os recursos mínimos necessários para sua aplicação. Na terceira, faremos uma descrição geral com atividades detalhadas aula por aula. Na quarta, relacionaremos as questões da atividade virtual com os conceitos de Probabilidade. Finalmente, na quinta seção, faremos as considerações finais.

\section{Caracterização}

Nesta seção apresentaremos os recursos mínimos necessários ao bom desenvolvimento da atividade proposta.

\subsection{Público alvo}

Essa proposta foi construída para professores aplicarem nas turmas do segundo ano do Ensino Médio, cujos alunos têm entre 15 e 18 anos. No entanto, se o professor achar adequado, pode aplicar os questionários para turmas de outros perfis.

\subsection{Pré-requisitos}

Nesta atividade é indispensável que os alunos já tenham estudado Análise Combinatória, operações entre conjuntos como união, interseção e diferença, bem como operações com números racionais.

Além disso, facilitaria a aplicação da atividade virtual na escola se esta possuísse um profissional responsável pela sala de informática, que poderia auxiliar o professor e os alunos com os computadores.

\subsection{Materiais e tecnologias}

Considerando a possibilidade em que a atividade virtual é realizada à distância, o aluno necessitará de um computador com o software necessário para executá-la (basta arrastar os aplicativos *.swf para qualquer navegador ${ }^{1}$ ). Cabe salientar que em todos os sistemas operacionais (Windows, Linux, etc) existem vários aplicativos com essa finalidade. Caso a atividade seja realizada na escola, esta deverá possuir uma sala de Informática com preferencialmente um equipamento para cada aluno. Além disso, mesmo que a atividade ocorra na escola, os alunos que possuem celulares, tablets, etc. com internet podem utilizá-los.

\section{Materiais}

1. Sala de Informática com computadores (preferencialmente um para cada aluno);

2. Sala de aula com lousa.

\subsection{Recomendações metodológicas}

Primeiramente, sem explorar conceitos e definições dos termos que envolvem a Probabilidade, o aluno será desafiado a responder questões relativas a uma moeda e às cartas de baralho através de um Questionário Virtual e Lúdico (QVL). Isso poderá ser feito à distância ou na sala de informática da escola.

Numa segunda aula, no ambiente escolar, as questões, antes virtuais, estarão impressas e, em grupos, será proposto aos alunos que as resolvam novamente. Depois de destinar alguns minutos para essa tarefa, o professor discute tais questões para que sejam conceituados e definidos os termos que a Probabilidade envolve. Todas as atividades necessitam da mediação e orientação do professor.

Em um terceiro momento, podem ser aprofundadas a história da Probabilidade, as árvores de possibilidades e a Lei de Bayes, bem como o professor pode sugerir um banco de questões para que aconteça o aprendizado. Como livro de apoio, o professor pode usar Morgado et al. (2004).

Finalmente, o professor pode usar o segundo aplicativo Questionário Virtual Formal (QVF) para explorar os conceitos e definições relativos à Probabilidade.

\subsection{Dificuldades previstas}

Caso a atividade virtual seja realizada na escola, devemos considerar a possibilidade de um computador ser utilizado por mais de um aluno.

Se a atividade virtual for realizada à distância, será necessário disponibilizar o aplicativo com tal atividade e verificar se todos os alunos têm pelo menos um aparelho no qual o programa pode ser executado. Caso contrário, pode ser sugerido aos alunos que visitem um colega que tenha.

\section{Descrição geral: Atividades}

Descrevemos a sequência de realização das atividades para a construção dos conceitos de Probabilidade. Sugerimos quatro atividades de duração variável.

\footnotetext{
${ }^{1}$ Os aplicativos podem ser solicitados aos autores por email.
} 


\subsection{Atividade 1: Aplicação do QVL}

- Tempo requerido: um período de 50 minutos caso seja aplicado na escola.

Observação: a previsão é de que o aluno não leve todo esse tempo para responder, mas é preciso considerar o tempo necessário para acomodar os alunos na sala de informática.

Para a aplicação da primeira atividade, os alunos serão encaminhados a uma sala com computadores, ou então, serão incentivados a executá-la à distância. Nesse momento, sem explorar os conceitos da Probabilidade, o educando será orientado a responder um questionário virtual que possui um formato lúdico.

O QVL é composto por 15 questões de múltipla escolha. À medida que o aluno vai respondendo, ele vai obtendo a resposta e avançando o nível, inclusive podendo, automaticamente, elevar o grau de dificuldade. De certa forma, o questionário, na forma em que é apresentado, é um jogo, pois ao término das quinze questões, o aluno se depara com um score. Nesse instante, o estudante pode iniciar novamente, caso queira melhorar seu aproveitamento e, essa repetição, não deixa de ser uma forma de estudo na busca por uma melhor pontuação.

Segundo Moura

\begin{abstract}
A união entre o jogo e a resolução de problemas está intimamente vinculada à intencionalidade do professor, que é um dos arquitetos do projeto pedagógico do trabalho coletivo da escola. Este projeto tem começo - a cultura primeira - e um fim - a cultura elaborada, sendo ambos móveis; trata-se do conhecimento em movimento. Aquele conhecimento que é síntese de um processo passa a ser começo de outros, num movimento crescente [...] combinar jogo e resolução de problemas [...] é muito mais que uma simples atitude, é uma postura que deve ser assumida na condução do ensino. [...] fazer isto é dar um sentido humano ao jogo, à resolução de problemas e, sendo assim, à Educação Matemática.(Moura (1992))
\end{abstract}

Nesta atividade em cada questão, o aluno verifica se acertou e, nesse caso, pode passar imediatamente para a próxima. Porém, caso erre, há uma revisão com a resposta comentada. Dessa forma, tanto o aluno que acertou, quanto aquele que errou, tem as mesmas condições de passar para a questão seguinte.

Além disso, a correção instantânea estimula a sequência desse desafio. Nesse sentido, segundo Van de Walle,

os estudantes devem resolver problemas não para aplicar matemática, mas para aprender nova matemática. Quando os alunos se ocupam de tarefas bem escolhidas baseadas na resolução de problemas e se concentram nos métodos de resolução, $\mathrm{o}$ que resulta são novas compreensões da matemática embutida na tarefa.(Walle (2009))

As figuras (1), (2) e (3) ilustram, respectivamente, a tela inicial do jogo do QVL no formato swf, uma tela de acerto indicando que o estudante está apto para responder a próxima questão (neste caso, a segunda), e uma mensagem erro para a resposta da questão 4 , onde há uma explicação relativa à resposta correta.

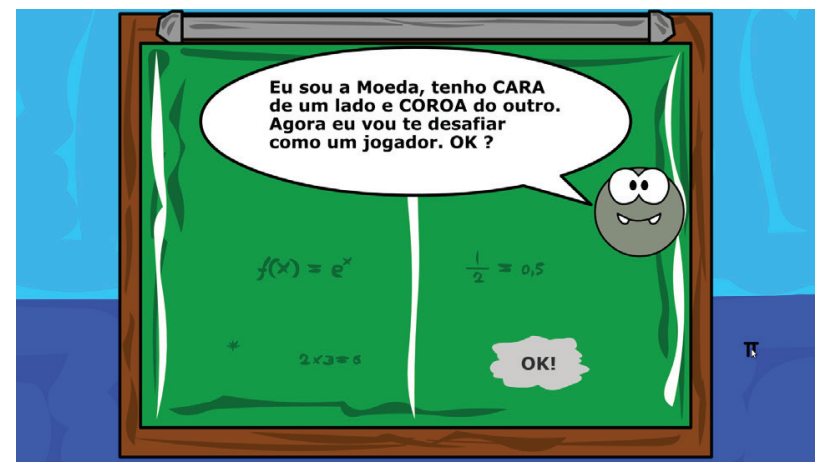

Figura 1: Tela inicial do jogo

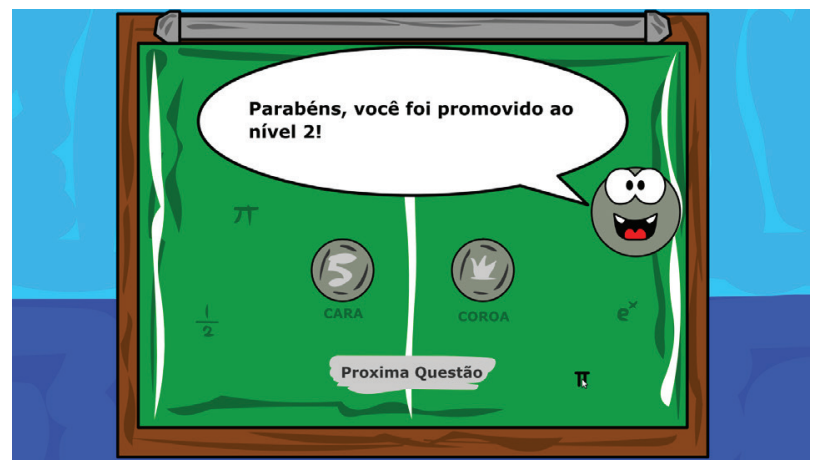

Figura 2: Exemplo de Feedback para acerto

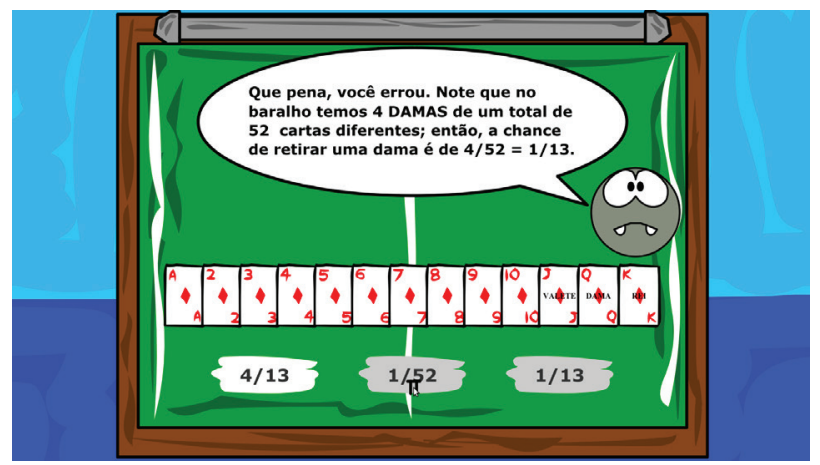

Figura 3: Exemplo de Feedback para erro 
As questões que compõem o QVL são:

1. Quando somamos a chance de obter cara, $\frac{1}{2}$, com a chance de obter coroa, $\frac{1}{2}$, temos:
a) $\frac{2}{4}$
b) 1
c) $\frac{3}{2}$

2. Conforme você pode observar abaixo, um naipe de baralho é composto por 13 cartas distintas. Sendo assim, a chance de retirar ao acaso (sem olhar) uma dama, dessas 13 cartas, é de:
a) $\frac{1}{13}$
b) $\frac{1}{12}$
c) $\frac{2}{13}$

3. De um naipe, pense que você quer retirar uma carta; então, a chance de retirar uma figura (dama, valete, rei) é de:
a) $\frac{1}{13}$
b) $\frac{3}{13}$
c) $\frac{3}{10}$

4. Vamos agora aumentar o número de cartas. Considere um baralho de 4 naipes, isto é, com 52 cartas; a chance de retirar uma dama qualquer é de:
a) $\frac{4}{13}$
b) $\frac{1}{52}$
c) $\frac{1}{13}$

5. A chance de retirar ao acaso uma figura (dama, valete, rei), entre as 52 cartas é de:
a) $\frac{3}{13}$
b) $\frac{3}{52}$
c) $\frac{1}{13}$

6. Se a chance de retirar uma figura é de $\frac{3}{13}$, então a chance de não retirar uma figura é de:
a) $\frac{10}{3}$
b) $\frac{10}{52}$
c) $\frac{10}{13}$

7. Quando somamos a chance de ter figura $\frac{3}{13}$ com a chance de não ter figura $\frac{10}{13}$, obtemos:
a) 1
b) $\frac{13}{26}$
c) $\frac{7}{13}$

8. A chance de retirar a dama de paus das 52 cartas é de:
a) $\frac{1}{13}$
b) $\frac{1}{52}$
c) $\frac{1}{51}$

9. A chance de retirar uma dama de um naipe vermelho é de:
a) $\frac{2}{13}$
b) $\frac{1}{26}$
c) $\frac{2}{50}$

10. A chance de aparecer uma dama ou um rei, ao retirar apenas uma carta do baralho é de:
a) $\frac{2}{13}$
b) $\frac{1}{26}$
c) $\frac{2}{50}$

11. A chance de sair uma dama preta ou um rei vermelho, ao pegar uma carta do baralho, pode ser expressa por:
a) $\frac{2}{13}$
b) $\frac{1}{26}$
c) $\frac{1}{13}$

12. A chance de sair uma dama preta ou um rei qualquer, ao se retirar uma carta do baralho, pode ser expressa por:
a) $\frac{6}{13}$
b) $\frac{3}{26}$
c) $\frac{5}{52}$

13. A chance de retirar uma dama ou uma carta vermelha do baralho é de:
a) $\frac{15}{26}$
b) $\frac{7}{13}$
c) $\frac{8}{13}$

14. Sabendo que a carta retirada foi uma figura, a chance de ser um valete é de:
a) $\frac{3}{13}$
b) $\frac{2}{3}$
c) $\frac{1}{3}$

15. Sabendo que um rei foi retirado, a chance de ser de copas é de:
a) $\frac{1}{4}$
b) $\frac{1}{13}$
c) $\frac{1}{3}$

\subsection{Atividade 2: Discussão do QVL}

- Tempo requerido: um período de 50 minutos.

Na segunda aula, formam-se pequenos grupos com $\mathrm{o}$ intuito de que os alunos respondam novamente às questões que antes apareciam de forma virtual. No entanto, as questões serão fornecidas impressas em papel. Isso retoma o assunto e prepara os alunos para a próxima etapa. No momento em que os alunos trabalham em grupo outras habilidades são desenvolvidas, tais como capacidade de cooperar, articulação da linguagem, sociabilidade, etc.

Nessa mesma aula, após a resolução das questões pelos alunos, o professor orientará e escolherá uma questão para discutir, instigando a reflexão e incentivando que os alunos formem conceitos e consequentemente surjam as definições de Probabilidade. É nesse momento que passamos a empregar o vocábulo Probabilidade. Médio

Conforme as Orientações Curriculares para o Ensino

ao estudar probabilidade e chance, os alunos precisam entender conceitos e palavras relacionadas 
à chance, incerteza e probabilidade, que aparecem na nossa vida cotidiana, particularmente na mídia. Outras ideias importantes incluem a compreensão de que a probabilidade é uma medida de incerteza, que os modelos são úteis para simular eventos, para estimular probabilidades, e que algumas vezes nossas intuições são incorretas e podem nos levar a uma conclusão equivocada no que se refere à probabilidade e à chance. (Brasil (2006))

Portanto, é fundamental que após o QVL se discutam os resultados e principalmente a diferença entre chance, incerteza e probabilidade.

\subsection{Atividade 3: Construção dos conceitos de Probabilidade}

- Tempo requerido: dois períodos de 50 minutos cada.

Na terceira aula, seguimos discutindo e definindo experiência aleatória, espaço amostral, evento, eventos mutuamente excludentes, união e intersecção entre eventos, bem como a Probabilidade Condicional. Para tal, o professor utiliza novamente as questões do QVL.

Para essa atividade, recomendamos que o professor assuma a forma de trabalho tradicional, utilizando a lousa e os comentários da seção 4 deste artigo.

\subsection{Atividade 4: Aplicação do Questionário Virtual Formal}

- Tempo requerido: um período de 50 minutos.

Nessa aula, o professor deve explorar atividades que exercitem os novos conceitos e definições. Para isso, recomendamos o Questionário Virtual Formal (QVF). Esse questionário possui a mesma disposição do QVL. No entanto, mudam apenas as questões que serão feitas de maneira tradicional.

1. A probabilidade de conseguir um quatro ao lançar um dado é de:
a) $\frac{2}{3}$
b) 1
c) $\frac{1}{6}$

2. A probabilidade de obter um número par ao lançar um dado é de:
a) $\frac{2}{3}$
b) $\frac{1}{2}$
c) $\frac{1}{3}$

3. A probabilidade de conseguir um número menor do que três ao lançar um dado é de:
a) $\frac{1}{3}$
b) 2
c) $\frac{1}{2}$

4. A probabilidade de obter um número maior do que três ao lançar um dado é de:
a) $\frac{1}{3}$
b) $\frac{1}{2}$
c) $\frac{2}{3}$

5. A probabilidade do número ser ímpar, sabendo que o número é primo é de:
a) $\frac{2}{3}$
b) 1
c) $\frac{1}{2}$

6. A probabilidade do número ser par, sabendo que o número é primo é de:
a) $\frac{2}{3}$
b) 1
c) $\frac{1}{3}$

7. Agora suponha que você vai lançar o dado duas vezes. O número de combinações possíveis é:
a) 12
b) 18
c) 36

8. Considerando o espaço amostral, referente ao lançamento de um dado duas vezes, $\{(1,1),(1,2)$, $(1,3),(1,4),(1,5),(1,6),(2,1),(2,2),(2,3),(2,4)$, $(2,5),(2,6),(3,1),(3,2),(3,3),(3,4),(3,5),(3,6)$, $(4,1),(4,2),(4,3),(4,4),(4,5),(4,6),(5,1),(5,2)$, $(5,3),(5,4),(5,5),(5,6),(6,1),(6,2),(6,3),(6,4)$, $(6,5),(6,6)\}$, a probabilidade de ocorrerem resultados iguais nos dois lançamentos é de:
a) $\frac{5}{36}$
b) $\frac{1}{6}$
c) $\frac{1}{2}$

9. Considerando o espaço amostral, referente ao lançamento de um dado duas vezes, $\{(1,1),(1,2)$, $(1,3),(1,4),(1,5),(1,6),(2,1),(2,2),(2,3),(2,4)$, $(2,5),(2,6),(3,1),(3,2),(3,3),(3,4),(3,5),(3,6)$, $(4,1),(4,2),(4,3),(4,4),(4,5),(4,6),(5,1),(5,2)$, $(5,3),(5,4),(5,5),(5,6),(6,1),(6,2),(6,3),(6,4)$, $(6,5),(6,6)\}$, a probabilidade de sair um número menor no primeiro lançamento é de:
a) $\frac{5}{12}$
b) $\frac{1}{2}$
c) $\frac{7}{12}$

10. Considerando o espaço amostral, referente ao lançamento de um dado duas vezes, $\{(1,1),(1,2)$, $(1,3),(1,4),(1,5),(1,6),(2,1),(2,2),(2,3),(2,4)$, $(2,5),(2,6),(3,1),(3,2),(3,3),(3,4),(3,5),(3,6)$, $(4,1),(4,2),(4,3),(4,4),(4,5),(4,6),(5,1),(5,2)$, $(5,3),(5,4),(5,5),(5,6),(6,1),(6,2),(6,3),(6,4)$, $(6,5),(6,6)\}$, a probabilidade da soma dos resultados dos dois lançamentos do dado ser ÍMPAR é de: 

a) $\frac{5}{12}$
b) $\frac{1}{2}$
c) $\frac{7}{12}$

11. Considerando o espaço amostral, referente ao lançamento de um dado duas vezes, $\{(1,1),(1,2)$, $(1,3),(1,4),(1,5),(1,6),(2,1),(2,2),(2,3),(2,4)$, $(2,5),(2,6),(3,1),(3,2),(3,3),(3,4),(3,5),(3,6)$, $(4,1),(4,2),(4,3),(4,4),(4,5),(4,6),(5,1),(5,2)$, $(5,3),(5,4),(5,5),(5,6),(6,1),(6,2),(6,3),(6,4)$, $(6,5),(6,6)\}$, a probabilidade da soma dos resultados dos dois lançamentos de dados ser igual a sete é de:
a) $\frac{5}{36}$
b) $\frac{1}{6}$
c) $\frac{7}{36}$

12. Considerando o espaço amostral, referente ao lançamento de um dado duas vezes, $\{(1,1),(1,2)$, $(1,3),(1,4),(1,5),(1,6),(2,1),(2,2),(2,3),(2,4)$, $(2,5),(2,6),(3,1),(3,2),(3,3),(3,4),(3,5),(3,6)$, $(4,1),(4,2),(4,3),(4,4),(4,5),(4,6),(5,1),(5,2)$, $(5,3),(5,4),(5,5),(5,6),(6,1),(6,2),(6,3),(6,4)$, $(6,5),(6,6)\}$, a probabilidade da soma dos resultados do lançamento dos dois dados ser igual a sete, sabendo que num dos dados saiu o número 3 é:
a) $\frac{11}{36}$
b) $\frac{1}{6}$
c) $\frac{2}{11}$

13. Considerando o espaço amostral, referente ao lançamento de um dado duas vezes, $\{(1,1),(1,2)$, $(1,3),(1,4),(1,5),(1,6),(2,1),(2,2),(2,3),(2,4)$, $(2,5),(2,6),(3,1),(3,2),(3,3),(3,4),(3,5),(3,6)$, $(4,1),(4,2),(4,3),(4,4),(4,5),(4,6),(5,1),(5,2)$, $(5,3),(5,4),(5,5),(5,6),(6,1),(6,2),(6,3),(6,4)$, $(6,5),(6,6)\}$, a probabilidade de se obter o número 2 num dado, sabendo que a soma dos resultados dos dois lançamentos é igual a sete é:
a) $\frac{1}{3}$
b) $\frac{7}{11}$
c) $\frac{6}{7}$

14. Em uma reportagem exibida no programa Fantástico, em 17/02/2013, foi afirmado que a probabilidade de um raio atingir uma pessoa na região amazônica é como escolher um número de um dado e o lançando, obter três vezes seguidas esse mesmo número (Fantástico (2013)). Assim, a probabilidade de uma pessoa receber tal descarga elétrica é de:
a) $\frac{1}{18}$
b) $\frac{1}{216}$
c) $\frac{1}{1.000}$

15. Mas não se desespere, segundo a mesma reportagem, nas demais regiões do país a probabilidade, em média, de uma pessoa receber uma descarga elétrica de um raio é como escolher um número de um dado e o lançando, obter oito vezes seguidas esse mesmo número (Fantástico (2013)). Nesse caso, a chance de ser atingido por um raio é de:
a) $\frac{1}{6^{8}}$
b) $\frac{1}{48}$
c) $\frac{1}{600.000 .000}$

Mesmo com a formalidade, acreditamos que o questionário irá chamar a atenção dos alunos. Isso se deve ao fato de que cada educando já possuirá ferramentas teóricas e estará desenvolvendo a atividade em um aplicativo que cativa a atenção desses estudantes.

Novamente, essa aula pode ser realizada como uma atividade à distância. É a sugestão para as escolas que seguem a proposta Pedagógica do Ensino Médio Politécnico (SEDUC/RS (2011-2014)).

\section{Construção dos conceitos e defini- ções de probabilidade}

Para concluir a sequência de atividades, sugerimos conceituar e definir os termos que são relacionados à Probabilidade e que são desenvolvidos durante a aplicação do QVL. Tais conceitos e definições serão compreendidos de forma mais natural pelos alunos, uma vez que estes já possuem o conhecimento informal.

Recomendamos aproveitar esse momento e comentar a resolução e as respostas das questões. O professor fica à vontade para utilizar suas ideias também, porém usaremos as questões já trabalhadas e outras, que podem facilitar a compreensão dos conceitos e das definições.

Além disso, a ordem dos termos a serem definidos pode ser alterada e as questões de apoio deverão ser lidas em voz alta.

\subsection{Experiências aleatórias}

Para conceituar experiências aleatórias, vamos usar a Questão 2 do QVL.

Conforme você pode observar abaixo, um naipe de baralho é composto por 13 cartas distintas. Sendo assim, a chance de retirar ao acaso (sem olhar) uma dama, dessas 13 cartas, é de:

Interagir da seguinte forma:

- Comentar: Quando retiramos uma carta entre essas 13 e repetimos o processo diversas vezes, estamos fazendo ........... (Esperar para ver se eles sugerem a palavra experiências). Caso contrário, o professor pode sugerir o termo e passar para o próximo item. 
- Perguntar: Se, por diversas vezes retirarmos uma carta entre essas 13, o resultado será sempre o mesmo? Esperar pelas respostas e, então, escrever na lousa:

Experiências aleatórias são resultados diferentes obtidos quando repetimos procedimentos sob as mesmas condições.

\subsection{Espaço amostral e evento}

Para conceituar espaço amostral e evento, usaremos a Questão 3 do QVL.

De um naipe, pense que você quer retirar uma carta; então, a chance de retirar uma figura (dama, valete, rei) é de:

- Perguntar: As 13 cartas seriam o espaço amostral ou o evento?

Definimos o espaço amostral como o conjunto de todos os resultados possíveis de uma experiência aleatória.

Já o evento pode ser definido como um subconjunto do espaço amostral. Em nossa questão, retirar uma figura seria um evento.

\subsection{Probabilidade}

Sugestão: A questão 5 do QVL pode ser utilizada para definir probabilidade na concepção clássica de Laplace.

A chance de retirar ao acaso uma figura (dama, valete, rei), entre as 52 cartas é de:

- Perguntar: Quantas cartas temos a nosso favor?

- Perguntar: Qual é o espaço amostral?

Podemos dizer que, conforme Laplace, probabilidade é igual ao quociente entre o número de casos favoráveis e o número de casos possíveis. Porém, essa definição somente é válida quando o espaço amostral possui um número finito de elementos.

\subsection{Eventos mutuamente excludentes}

Neste caso, usaremos novamente a Questão 5 do QVL.

A chance de retirar ao acaso uma figura (dama, valete, rei), entre as 52 cartas é de:

- Perguntar: Se retiramos uma única carta do baralho, podemos obter uma figura e um número ao mesmo tempo?

A resposta correta é não. Definimos eventos mutuamente excludentes como aqueles que não podem ocorrer simultaneamente.

\subsection{União entre eventos mutuamente exclu- dentes}

Sugestão: A união entre eventos mutuamente excludentes será definida através da questão 10 do QVL.

A chance de aparecer uma dama ou um rei, ao retirar apenas uma carta do baralho é de:

- Anotar na lousa:

Evento A: retirar uma dama;

Evento B: retirar um rei.

- Perguntar: Podemos retirar uma dama que seja ao mesmo tempo um rei? Os alunos devem responder não. Afirmar: $\mathrm{Ou}$ seja, a interseção entre os eventos é vazia. Esperamos pela resposta para concluir que $A$ e $B$ são eventos mutuamente excludentes.

Assim, a probabilidade de $A$ união $B$ é igual a probabilidade de $A$ mais a probabilidade de $B$, ou seja,

$$
P(A \cup B)=P(A)+P(B) .
$$

\subsection{União entre eventos}

Usamos a Questão 13 do QVL para definir união entre eventos.

A chance de retirar uma dama ou uma carta vermelha do baralho é de:

- Anotar na lousa:

Evento A: retirar uma dama;

Evento B: retirar uma carta vermelha.

- Perguntar: Podemos retirar uma dama que seja ao mesmo tempo uma carta vermelha? A resposta correta é sim. Após a resposta dos alunos, podemos complementar que a intersecção entre $A$ e $B$ não é o conjunto vazio.

Assim, a probabilidade de $A$ união $B$ é igual a probabilidade de $A$ mais a probabilidade de $B$ menos a probabilidade de $A$ intersecção $B$, ou seja,

$$
P(A \cup B)=P(A)+P(B)-P(A \cap B) .
$$

Este resultado se deve ao fato de ao contarmos as damas, obtemos as duas damas vermelhas, que também foram incluídas nas cartas vermelhas; logo, elas precisam ser subtraídas, já que foram consideradas duas vezes.

\subsection{Probabilidade entre 0 e 1}

Para definir a probabilidade entre 0 e 1 não utilizaremos uma questão específica, mas sim analisaremos os resultados de diversas questões. 
- Perguntar: Qual é o menor e qual é o maior resultado obtido como resposta das questões do QVL? Esperamos que surja uma resposta e, então, complementamos com o que segue.

- Anotar na lousa:

$$
\begin{aligned}
& S \text { : espaço amostral; } \\
& A \text { : evento qualquer. }
\end{aligned}
$$

Podemos definir que 0 é menor ou igual a probabilidade de $A(P(A))$ que é menor igual a $1(0 \leq \mathrm{P}(\mathrm{A}) \leq$ 1). $P(A)=0$ significa que o evento nunca acontece $\mathrm{e}$ $P(A)=1$ é a certeza de que o evento acontece. Portanto, afirmar que a probabilidade de que $S$ ocorre certamente é o mesmo que escrever $P(S)=1$.

\subsection{Probabilidade condicional}

Na definição de probabilidade condicional, usaremos a Questão 14 do QVL.

Sabendo que a carta retirada foi uma figura, a chance de ser um valete é de:

- Afirmar: Temos, assim, um espaço amostral reduzido a 12 figuras diferentes das quais queremos um Valete (há 4 no baralho). Logo, a resposta é $\frac{1}{3}$. Vamos analisar o seguinte:

- Anotar na lousa:

$A$ : retirar um valete: $P(A)=\frac{1}{13}$;

$B$ : retirar uma figura: $P(B)=\frac{3}{13}$;

$A$ e $B: P(\mathrm{~A} \cap \mathrm{B})=\frac{1}{13}$.

- Perguntar: Com esses dados, como chegar à resposta $\frac{1}{3}$ ?

Temos duas possibilidades, uma é $\frac{P(A)}{P(B)}$ ou $\frac{P(A \cap B)}{P(B)}$.

Note que $P(A \cap B)$ é diferente de $P(A) \times P(B)$. Isso caracteriza eventos dependentes.

\subsection{Eventos independentes}

Para definir eventos independentes, utilizaremos a Questão 15 do QVL.

Sabendo que um rei foi retirado, a chance de ser de copas é de:

- Anotar na lousa:

$A$ : retirar uma carta de copas: $P(A)=\frac{1}{4}$;

$B$ : retirar um rei: $P(B)=\frac{1}{13}$;

$A$ e $B: P(\mathrm{~A} \cap \mathrm{B})=\frac{1}{52}$.
- Perguntar: Com esses dados, como chegar à resposta $\frac{1}{4}$ ? Temos assim, também dois casos: $P(A)$ ou $\frac{P(A \cap B)}{P(B)}$. Logo, notamos que o segundo apareceu na seção anterior e também nessa.

Note que $P(A \cap B)$ é igual de $P(A) \times P(B)$. Isso caracteriza eventos independentes. $\mathrm{E}$, nesse caso, temos

$$
P(A \mid B)=\frac{P(A \cap B)}{P(B)}=\frac{P(A) \times P(B)}{P(B)}=P(A) .
$$

Portanto, das últimas duas subseções, segue que a probabilidade condicional pode ser expressa por:

$P(A \mid B)=\frac{P(A \cap B)}{P(B)}$.

\section{Considerações finais}

Neste trabalho disponibilizamos dois aplicativos (QVL e QVF) para auxiliar no ensino de Probabilidade. Além disso, discutimos sua aplicação e formas de apresentar os conceitos relacionados.

Inicialmente, a proposta de apresentar ao aluno o conteúdo informalmente para depois formalizá-lo, utiliza os problemas para ensinar Matemática e a Matemática para resolver problemas. Portanto, estamos alicerçados em BRASIL (1997), pois esses elegem a resolução de problemas como peça central no ensino da Matemática.

Ao longo dessa proposta, apresentamos uma alternativa de estudo sobre a Probabilidade incomum nos livros didáticos. Associando o jogo com a resolução de problemas, o aprendizado se torna mais proveitoso e incorpora o aluno como sujeito que colabora na construção do seu próprio conhecimento.

Por fim, de acordo com BRASIL (1997), utilizar a estratégia do jogo motiva os alunos desencadeando o aprendizado, ainda mais unindo a resolução de problemas. Por tudo isso, consideramos nossa proposta viável, conscientes de que não existe um único caminho, mas que existem diversas possibilidades para o ensino de Probabilidade. Podem e devem ser exploradas novas metodologias de ensino pelos professores, acrescentando, assim, qualidade ao ensino e, simultaneamente, aumentando o conhecimento adquirido pelo indivíduo.

\section{Referências}

BOYER, C. B., 1974. História da Matemática. Edgard Blucher,São Paulo.

BRASIL, 1997. Parâmetros Curriculares Nacionais: Matemática. Secretaria da Educação Fundamental, Brasília. 
BRASIL, 2006. Orientações Curriculares para o Ensino Médio: Ciências da Natureza, Matemática e suas Tecnologias. Ministério da Educação, Brasília.

CAETANO, P. A. S., Paterlini, R. R., 2010. Matemática na prática: Jogo dos discos.

CORBALÁN, F., 2002. Juegos Matemáticos para secundaria y Bachillerato. São Paulo, Editorial Síntesis, Madri.

EVES, H., 2002. Introdução à História da Matemática. UNICAMP, Campinas.

FANTÁSTICO, 2013. O país dos raios: Raios matam 130 pessoas e deixam mais de 200 feridas por ano no Brasil. URL http://g1.globo.com/fantastico/noticia/ 2013/02/raios-matam-130

LOPES, J. M., 2011. Uma proposta didático-pedagógica para o estudo da concepção clássica de probabilidade.

LOPES, J. M., TEODORO, J. V., DE CARVALHO REZENDE, J., 2011. Uma proposta para o estudo de probabilidade no ensino médio.

MORGADO, A. C. O., DE CARVALHO, J. B. P., CARVALHO, P. C. P., FERNANDES, P., 2004. Análise Combinatória e Probabilidade. SBM, Rio de Janeiro.

MOURA, M. O., 1992. O Jogo e a Construção do Conhecimento Matemático. FDE, São Paulo.

SEDUC/RS, 2011-2014. Proposta Pedagógica para o Ensino Médio Politécnico e Educação Profissional integrada ao Ensino Médio - 2011-2014. Secretaria da Educação, Porto Alegre. URL http://www.educacao. rs.gov.br/dados/ens_med_proposta.pdf

WALLE, J. A. V., 2009. Matemática no ensino fundamental: formação de professores e aplicação em sala de aula. Artmed, Porto Alegre. 